\title{
DE LA CARICATURA DE PRENSA EXTRANJERA AL MUSEO HISTÓRICO NACIONAL. ALGUNOS ANTECEDENTES HISTÓRICOS EN TORNO A LA POLÉMICA SOBRE LA REPRESENTACIÓN GRÁFICA DE AUGUSTO PINOCHET EN EL ESPACIO PÚBLICO*
}

\author{
FROM THE CARICATURE OF THE FOREIGN PRESS TO THE NATIONAL \\ HISTORICAL MUSEUM. SOME HISTORICAL BACKGROUND ON \\ THE CONTROVERSY OVER THE REPRESENTATION OF AUGUSTO \\ PINOCHET IN THE PUBLIC SPACE
}

\section{MANUEL GÁRATE CHATEAU**}

RESUmen: En este artículo se sostiene que la polémica surgida en torno a la mención a Augusto Pinochet en la muestra del Museo Histórico Nacional del año 2018, no se puede comprender sin tomar en cuenta la imagen internacional del personaje construida históricamente a partir de 1973. Para ello nos apoyamos en un corpus constituido por caricaturas de prensa provenientes de diversos medios escritos extranjeros. El objetivo principal es dar cuenta de cómo se fue construyendo dicha imagen y la dificultad creciente que existe en mostrar a Augusto Pinochet en el espacio público nacional. Para ello, se utilizará un análisis diacrónico e iconográfico. Esto nos permitirá demostrar la paulatina coincidencia que se ha producido entre la imagen negativa que existe sobre Pinochet fuera del país y aquella construida localmente.

Palabras clave: Dictadura, Chile, caricatura política, Augusto Pinochet, representaciones.

Aвstract: This article argues that the controversy that arose regarding the mention of Augusto Pinochet in the 2018 Museo Histórico Nacional (Chile) exhibition cannot be understood without taking into account the international historically constructed image of the character since 1973. Relying on a corpus of press cartoons from various foreign written media, this paper explores how this image was built, and the existing and growing difficulties of showing Augusto Pinochet in the national public space. A diachronic and iconographic analysis allows us to demonstrate the gradual coincidence between the international negative image of Pinochet with the locally built representation.

KeYwords: Dictatorship, Chile, political cartoons, Augusto Pinochet, representations.

Recibido: 2019-02-01. Aceptado: 2020-06-25.

* Este artículo recibió financiamiento y apoyo del Centro de Estudios de Conflicto y Cohesión Social, COES, ANID/FONDAP/15130009.

** Doctor en Historia. Académico del Instituto de Historia, Pontificia Universidad Católica de Chile, Santiago, Chile. Correo electrónico: mgarate@uc.cl. Orcid: https://orcid.org/0000-0002-0016-596X. 


\section{1. ¿POR QUÉ ESTUDIAR LA IMAGEN INTERNACIONAL DE PINOCHET A TRAVÉS DE LA CARICATURA POLÍTICA DE PRENSA?}

L A CARICATURA POLÍtica en medios de comunicación escritos representa una de las manifestaciones más distintivas de la prensa escrita, es decir, de aquella surgida en Europa con posterioridad a la Revolución Francesa y en aquellas sociedades donde se consolidó la idea de la libertad de expresión como principio fundamental de los regímenes democráticos. Desde un punto de vista teórico, reconocidos autores tales como el historiador del arte Ernst Gombrich (1984, 2007), y de historiadores de la cultura como Delporte et al. (2010), Van Ypersele (1993), Baridon \& Guédron (2006), han sostenido que la caricatura de prensa corresponde a un tipo particular de lenguaje visual, el cual posee la capacidad de sintetizar en una imagen toda una serie de estereotipos y situaciones políticas a través del humor. La caricatura política personifica los conceptos y adopta generalmente la disputa maniquea entre el bien y el mal, donde la personificación de este último suele ser más interesante justamente por la infinidad de recursos disponibles (monstruosidad, deformidad, ridiculez, bestialidad, etc.), tal como lo plantea Montealegre (2008) en sus diversos escritos sobre la caricatura chilena. La figura de Augusto Pinochet - por encima de otros gobernantes autoritarios- cumplió este rol por más de treinta años en algunos de los principales periódicos y revistas europeas. Esto se aprecia sobre todo a partir del incidente de su detención en Londres (1998-2000).

El objetivo principal de este artículo, y que corresponde además a la pregunta de investigación, se refiere a cómo se generó la imagen pública negativa de Augusto Pinochet a nivel internacional, especialmente a partir de fuentes iconográficas (caricaturas de prensa), y posteriormente relacionar esto con la polémica del Museo Histórico Nacional (MHN) del año 2018. Recordemos que esta se inició producto de la inclusión del personaje en una muestra sobre la idea de la libertad en la historia de Chile. Un segundo objetivo de este artículo se refiere a demostrar la dificultad de la inclusión de la imagen o referencia a Augusto Pinochet en una muestra o debate público en Chile sin que se desaten emociones más allá de todo debate académico. 


\section{EL CONTEXTO DE LA POLÉMICA}

El debate público en torno a la exposición "Hijos de la Libertad" (2018), del MHN, donde aparecía (solo al final de recorrido y entre otras imágenes) una fotografía de Augusto Pinochet y una cita suya sobre la libertad, generó un fuerte debate en redes sociales en torno a la representación de la dictadura militar en el espacio público. La polémica llegó rápidamente a la prensa escrita y a los medios de comunicación, donde principalmente se desarrolló a través de diversas columnas, al mismo tiempo que el gobierno de Sebastián Piñera, a través de su Ministerio de Cultura, reaccionó despidiendo al director del MHN. Diversas sensibilidades e interpretaciones han surgido del debate, algunas de ellas sobrepasando la tradicional división entre defensores y críticos de la dictadura. Afloró también la cuestión del revisionismo, del contexto histórico y del rol que tuvieron los agentes del Estado que actuaron como perpetradores de crímenes de lesa humanidad durante las décadas de 1970 y 1980.

Los estudios sobre las repercusiones y representaciones del 11 de septiembre chileno en el mundo han ido aumentando significativamente desde fines de la década de 1990, y sobre todo a partir de la conmemoración de los 30 años del golpe de Estado en 2003. Esto se vio acrecentado con la reciente conmemoración de los cuarenta años del fin de la Unidad Popular durante el año 2013. Una serie de coloquios y seminarios se realizaron en diferentes partes del mundo para dar cuenta de las influencias y conexiones que los eventos de Chile tuvieron a nivel internacional, en el desarrollo de la Guerra Fría y en el desenvolvimiento de la historia reciente del país. Sin lugar a dudas, las sociedades europeas fueron las que más se sensibilizaron con el drama del golpe de Estado, la muerte de Salvador Allende y la represión política posterior (Joignant, 2007). Desde una mirada crítica a la prensa europea, Vayssière (2005) ha sostenido que los medios de prensa europeos, especialmente los franceses, han estado tradicionalmente marcados por una pasión extrema respecto de la experiencia histórica de la Unidad Popular y de la dictadura encabezada por el general Augusto Pinochet, alterando toda lectura neutral de los acontecimientos. Sin compartir necesariamente la interpretación política que hace este autor francés sobre el fenómeno, es indudable la existencia de un alto grado de pasión respecto 
de la cobertura de los sucesos de Chile en Francia, Italia, Inglaterra y las dos Alemanias (oriental y occidental).

Los eventos del 11 de septiembre de 1973 fueron rápidamente difundidos a todo el planeta por televisión, radio, cine, fotografías y prensa escrita ${ }^{1}$. Basta recordar las innumerables imágenes y películas que nos muestran los tanques rodeando el palacio de La Moneda, el bombardeo aéreo del edificio y su posterior incendio, el fin de una de las más largas repúblicas democráticas de América Latina, y finalmente la trágica muerte del Presidente Salvador Allende, quien se negó a abandonar el palacio presidencial ante la amenaza del asalto y el desalojo. Los eventos parecen haberse desarrollado como pensados para un guión cinematográfico: la conspiración, el drama, las víctimas, el héroe póstumo, y finalmente a las pocas horas: la imagen de los líderes golpistas y, sobre todo, de quien apareció ante el mundo como el responsable principal: el general Augusto Pinochet flanqueado por los otros miembros de la junta militar. Todo se desarrolló dramáticamente y en el transcurso de unas pocas horas.

\section{LA CONSTRUCCIÓN DE LA IMAGEN DE PINOCHET EN LA PRENSA INTERNACIONAL}

Para entender la influencia de la imagen de la prensa respecto de Chile y de Pinochet fuera del país, debe tenerse en cuenta, además de los factores políticos e ideológicos, una cuestión estética fundamental. Hay que pensar en lo que significó para la Europa de postguerra el uniforme militar de Pinochet con claras evocaciones prusianas, y sus reconocibles anteojos oscuros. Con ello, la imagen internacional de la dictadura chilena se comenzó a configurar desde los primeros días posteriores al Golpe. Si a lo anterior se agrega además la feroz represión a los militantes y simpatizantes de la UP, el cuadro quedaba bien definido (Karmy, 2007). Por todo lo anterior, resultaba difícil y poco aconsejable (incluso para los partidos de la derecha democrática europea) apoyar directamente a la dictadura chilena, incluso dentro del contexto de la Guerra Fría y el combate a las fuerzas del campo socialista. Si a lo anterior se sumaba el hecho de que el proyecto marxista

\footnotetext{
${ }^{1}$ Ver el interesante trabajo de Ayala y Rojas (2017) sobre la cobertura de los golpes de Estado de Chile y Argentina en Venezuela en los años 70. A nivel internacional de la política mundial las obras de Alan Angell (2003 y 2013) dan cuenta de las repercusiones de los acontecimientos de Chile. En relación a la prensa francesa, uno de los mejores trabajos sobre la cobertura del golpe de Estado es el de Carolina Amaral (2015), específicamente respecto de la cobertura televisiva.
} 
de Allende había sido visto por la izquierda socialdemócrata europea como una alternativa no violenta al modelo revolucionario cubano, el golpe de Estado aparecía como una respuesta desproporcionada y brutal al desafío planteado por la Unidad Popular.

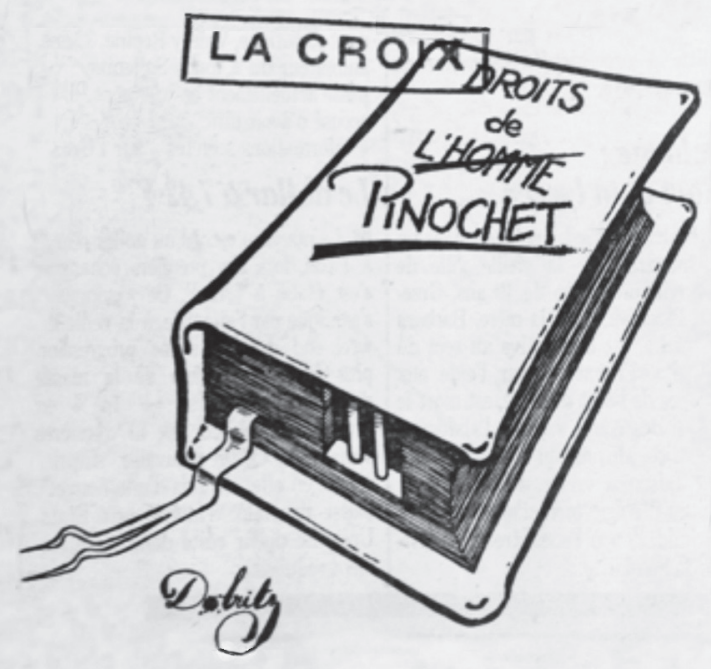

Figura 1. Jean Dobritz, La Croix, 18/05/1983 (en M. Gárate, 2015).

Pocos días después del golpe de Estado, el general Augusto Pinochet aparecía en la tradicional ceremonia católica del Te Deum, vestido de uniforme, con anteojos oscuros, y flanqueado por sus edecanes y guardaespaldas. En un acierto fotográfico de alcance mundial inédito, el fotógrafo holandés Chas Gerretsen capturó el instante exacto en que Pinochet, ya sentado, cruzaba sus brazos y con un rostro duro miraba hacia el sector donde estaba el reportero gráfico (Gutiérrez, 2013). Fue ahí que se gestó la imagen más reconocida e indeleble del dictador: rodeado de uniformes, con su mirada oculta tras los anteojos y con el ceño fruncido. Hasta el final de sus días Pinochet debió lidiar con las miles de copias, reproducciones y reinterpretaciones de esta imagen, incluso hoy en día considerada como una especie de ícono del mal y del autoritarismo en la cultura popular. 


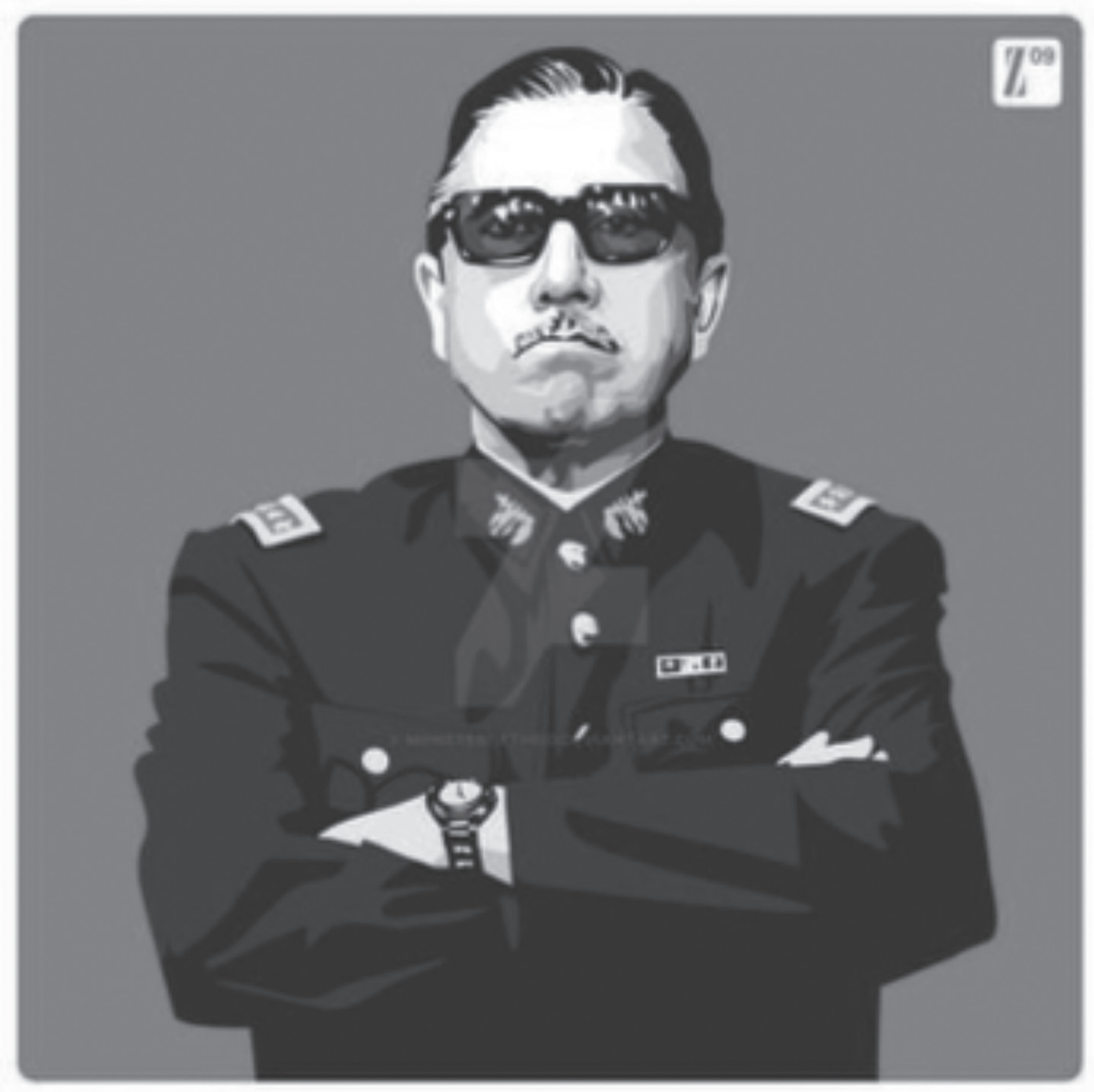

Figura 2. Monsteroftheid (2018). Ilustración artística de Pinochet derivada de la foto original de Chas Gerretsen (1973). Recuperada de Devian Art. Disponible en: https://www.deviantart.com/monsteroftheid/art/Pinochet-123194320.

Durante más de una década Pinochet fue representado y caricaturizado principalmente a partir de esta fotografía en buena parte de los medios escritos occidentales ${ }^{2}$. A esto se agregaba la intensa campaña que los exiliados chilenos llevaron a cabo en diversas partes del mundo en contra de la dictadura, y especialmente de quien la encabezaba. Pero la estética fue solo uno

${ }^{2}$ Una de las viñetas más conocidas sobre el golpe de Estado en Chile se publicó en el diario francés Le Monde (13-11-1973). Fue dibujada por el reconocido caricaturista Plantu (Jean Plantureaux). En ella vemos a un sujeto fusilado amarrado a un poste que tiene la forma del territorio de Chile. Esta simple imagen se convirtió en una de las metáforas visuales más recordadas del periodo. 
de los elementos que dieron forma a la imagen del régimen en el exterior. Basta pensar que el propio Pinochet había sido nombrado por Salvador Allende como Comandante en Jefe del Ejército pocas semanas antes del golpe de estado por recomendación expresa de su antecesor (Carlos Prats), y que posteriormente se sumaría a la conspiración golpista que terminó con el palacio presidencial bombardeado, Allende suicidado y cientos de miles de prisioneros políticos a lo largo del país ${ }^{3}$. Pocos imaginaron que la represión se extendería por al menos otra década, sumando exilio, tortura, prisión y desaparición forzada de militantes y simpatizantes de izquierda.

Existen otros elementos que hicieron de Pinochet un personaje singular a nivel internacional. En primer lugar, y a diferencia de otras dictaduras latinoamericanas de la época, Pinochet encabezó de manera unipersonal todo el periodo de la dictadura, contando con el apoyo del resto de las Fuerzas Armadas. Pero no fue un régimen colegiado, donde el poder ejecutivo fuese compartido por los otros comandantes en jefe. La junta militar chilena tuvo relevancia solo como órgano consultivo y legislativo, pero Pinochet tuvo siempre la última palabra, y se deshizo de quienes pudieran disputarle dicho poder, como sucedió con el general de la Fuerza Aérea, Gustavo Leigh en 1977. Esta personalización del régimen, sumada a su larga extensión temporal (1973-1990), solo superada por la dictadura paraguaya de Alfredo Stroessner, convirtió al general chileno en una suerte de ícono representativo de los regímenes autoritarios latinoamericanos del periodo 4 . La cuestión de la represión a los opositores también jugó un papel clave, pues si bien la dictadura chilena, en términos de número de víctimas, no fue la más sanguinaria, sí generó una imagen muy fuerte respecto de la desaparición forzada de personas y la violencia extrema contra partidos y agrupaciones de izquierda como el MIR, el Partido Comunista y algunas corrientes del Partido Socialista. Pinochet daba además conferencias de prensa y se fotografiaba regularmente en uniforme, con lentes oscuros y reflejando una imagen de duro e inflexible. Muy tardíamente el régimen

\footnotetext{
${ }^{3}$ El semanario inglés The Observer dedicó una página completa al caso de Chile el día 16 de septiembre de 1973, donde además se incluyó una viñeta que comparaba a Allende con Alexander Dubcek, el líder reformista de la antigua Checoslovaquia, quien se vio obligado a dimitir debido a la invasión del ejército soviético que puso fin a la llamada Primavera de Praga en 1968.

${ }^{4}$ La conocida revista norteamericana The New York Review of Books dedicó un número especial al caso de Chile el 01 de noviembre de 1973, criticando duramente a las nuevas autoridades militares del país, y sobre todo a Pinochet. Se incluyó un dibujo a portada completa donde se lo muestra como una especie de carnicero con uniforme militar. La viñeta es de autoría del famoso y premiado caricaturista David Levine. El dibujo acompañaba un artículo titulado "La muerte de Chile" del columnista Laurence Birns (1973).
} 
comprendió el alcance que esta imagen iba a generar en el exterior, y de la cual nunca se pudo deshacer.

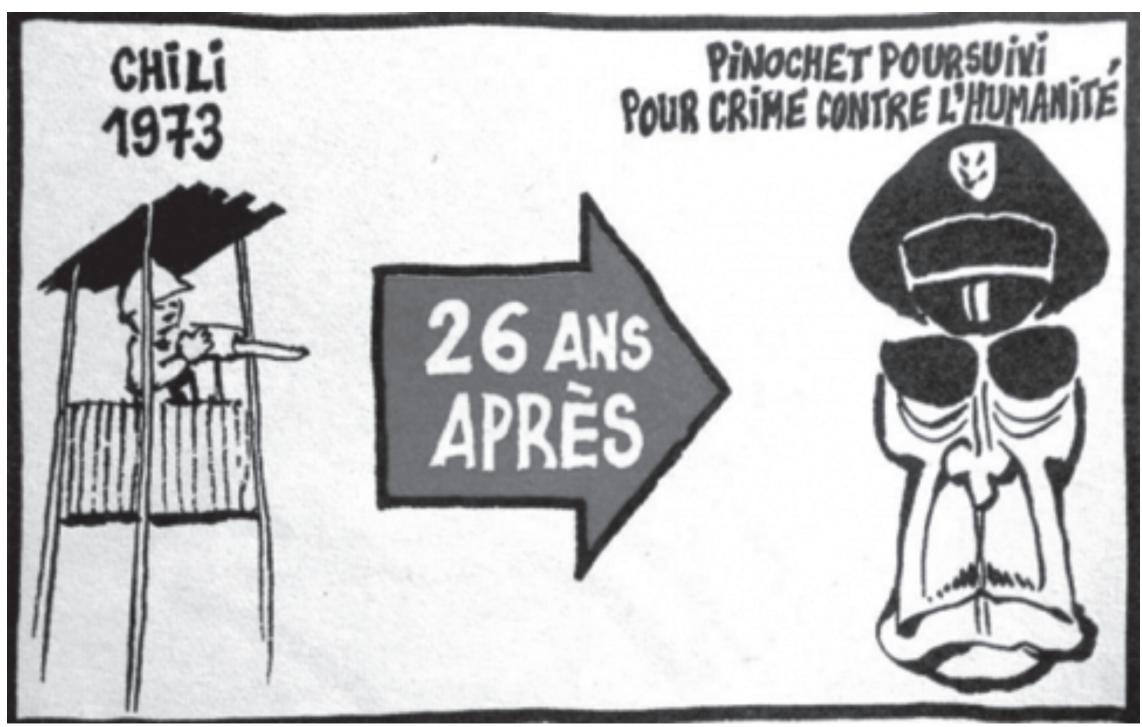

Figura 3. Riss, Charlie Hebdo, 02/06/1999 (en M. Gárate, 2015).

Otra cuestión que impactó en la imagen caricatural de Pinochet fue la asociación inmediata que se hizo en la prensa europea entre la dictadura chilena y el fascismo europeo de entreguerras, sumada a la dura crítica de los países del mundo socialista a la junta militar y a quienes apoyaron el derrocamiento de un gobierno que se había definido como marxista, aunque de una manera bastante sui generis. A nivel interno (nacional), la figura de Pinochet no era menos controvertida, si bien una parte importante de la población se manifestó a favor del régimen, incluso en las postrimerías del mismo. Baste recordar que en 1988, casi un 44\% de los electores (con sistema de inscripción voluntaria y voto obligatorio), apoyaron la continuidad de Augusto Pinochet como Presidente de la República hasta marzo de 1997. Incluso habiendo perdido el plebiscito, Pinochet continuó siendo un actor político fundamental de la transición democrática hasta el año 2000. Mantuvo su cargo como Comandante en Jefe del Ejército hasta principios de 1998, y asumió como senador designado en marzo del mismo año, siendo, en los hechos, el líder fáctico de la derecha y de la oposición al gobierno de Eduardo Frei Ruiz Tagle.

Solo los acontecimientos inesperados del arresto en Londres de octubre 
de 1998, cambiaron el curso de la historia reciente de Chile y catapultaron nuevamente la imagen de Pinochet al panteón de los dictadores políticos más recordados del siglo XX. Si bien la imagen de Pinochet al interior del país vivía esta dualidad de representación entre el "cruel dictador" y el "salvador de la patria", buena parte de los medios de prensa occidentales más reputados reflejaban indudablemente la primera versión. Lo que más afectó la imagen de Pinochet al interior del país e incluso entre sus partidarios, no fue el problema de la violación masiva de los derechos humanos entre 1973 y 1990, sino que fundamentalmente las repercusiones del llamado caso Riggs (2003-2004), que destapó las cuentas millonarias que mantenía Pinochet en el extranjero a través de nombres falsos y testaferros. En definitiva, fue el factor del enriquecimiento ilícito lo que terminó de hundir su imagen, sin contar que algunos de sus oficiales subordinados directos que estaban involucrados en crímenes de DD.HH., estaban en la cárcel o siendo procesados, sin que Pinochet asumiera, ante la justicia, ninguna responsabilidad del mando.

La muerte de Augusto Pinochet en diciembre de 2006 volvió a dividir a la opinión pública chilena, si bien una importante encuesta ha mostrado que lentamente, aunque de manera creciente, los chilenos (76\%) se han formado una mala opinión de Pinochet y de su régimen (MORI, 2015). A nivel internacional, al menos entre las grandes potencias occidentales, la prensa de dichos países ya se había formado una imagen muy negativa del dictador desde mediados de la década de 1970. No solo el exilio y la represión interna del periodo tuvieron un efecto clave en esta representación del dictador chileno, sino que también los atentados cometidos en el extranjero por agentes del régimen en contra del general Carlos Prats en Argentina, el político demócratacristiano Bernardo Leighton en Italia, y -sobre todoOrlando Letelier en la capital de Estados Unidos en septiembre de 1976. La osadía y extraordinaria violencia de estas acciones instaló la idea de que la dictadura chilena era un peligro a nivel internacional, y que podía alterar los frágiles equilibrios de la Guerra Fría a través de estas operaciones unilaterales en el extranjero.

\section{COMPRENDER LA POLÉMICA A TRAVÉS DE LA HISTORIA RECIENTE}

Todo lo anterior nos permite entender la envergadura y la representación que el mundo occidental se hizo del general Pinochet, especialmente a partir de sus medios de prensa, sobre todo escritos. La caricatura política, en 
tal sentido, fue una de las herramientas preferidas de los caricaturistas para criticar a la dictadura chilena y la situación del país, a través de la representación de Augusto Pinochet. Pocos días después del golpe la imagen del general y los anteojos oscuros se difundió por el mundo y dio pie a un tipo de interpretación donde la cuestión de la intervención norteamericana y el carácter "fascista" (a partir de la mirada europea) de la junta militar fueron los aspectos que más resaltaban en estas primeras viñetas. Posteriormente, la cuestión del conflicto ideológico este-oeste fue cediendo paso a una denuncia sobre las violaciones a los derechos humanos que ocurrían en Chile a manos de agentes del Estado, y el papel que le cabía al régimen en su ejecución y, al mismo tiempo, su negación ante las instancias internacionales como Naciones Unidas o la Cruz Roja Internacional.

En Chile, la figura de Pinochet, al menos durante la década de 1970, no podía ser criticada de manera pública debido a la censura y a la acción represiva de los organismos de inteligencia del régimen. Solo a partir de fines de la década de 1970 e inicios de los 80, y producto de la presión internacional, el gobierno comenzó a abrir algunos espacios de disidencia, aunque estrictamente controlados. Poco a poco algunas revistas y medios alternativos comenzaron a referirse al régimen, y a Pinochet en particular, en un tono jocoso. Sin embargo, esta crítica fue bastante marginal y restringida a algunos pequeños grupos opositores hasta el comienzo de la crisis económica de 1982 y el periodo inmediatamente posterior, cuando medios disidentes tomaron fuerza y el humor gráfico también emergió como una de las formas de crítica pública más directas en contra de las autoridades del régimen y de Pinochet en especial. Medios escritos como las revistas HOY, Análisis, APSI, Cauce y el periódico Fortín Mapocho, si bien eran leídos por un público restringido (opositor y letrado), reflejaron en sus páginas, a veces con gran agudeza, una crítica ácida al régimen y su principal representante (Araya, 2007).

Durante la década de los 90, mientras el país vivía su compleja transición a la democracia, la imagen de Pinochet en el extranjero comenzó a diluirse y a perder importancia, pues Chile dejó de ser un punto de atención de la política mundial y la misma figura del exdictador se incorporó al nuevo régimen como una suerte de figura tutelar del legado institucional de la dictadura militar. Fue así como siguió siendo una figura política de la contingencia durante ocho años como Comandante en Jefe del Ejército, para después asumir como senador designado según lo estipulaba la Constitución elaborada durante la dictadura. Su incorporación y legitimación en la nueva democracia parecía asegurada hasta los inesperados e imprevistos 
eventos de Londres en $1998^{5}$. El tema de las violaciones a los DD.HH., que muchos dirigentes políticos vieron como definitivamente cerrado con el Informe de la Comisión Nacional de Verdad y Reconciliación de 19916, emergió nuevamente con gran fuerza tanto en Chile como en el extranjero. Cientos de columnas, reportajes y análisis se escribieron sobre Chile y la dictadura durante los meses de detención de Augusto Pinochet en Inglaterra. Durante este singular periodo de tiempo, que transcurrió entre octubre de 1998 y marzo de 2000, se discutió más sobre justicia, verdad y reparación que durante toda la década anterior. En esta situación se muestra a Pinochet a través del reconocido caricaturista estadounidense Danziger en el periódico Los Angeles Times en su edición del 26 de noviembre de 1998.

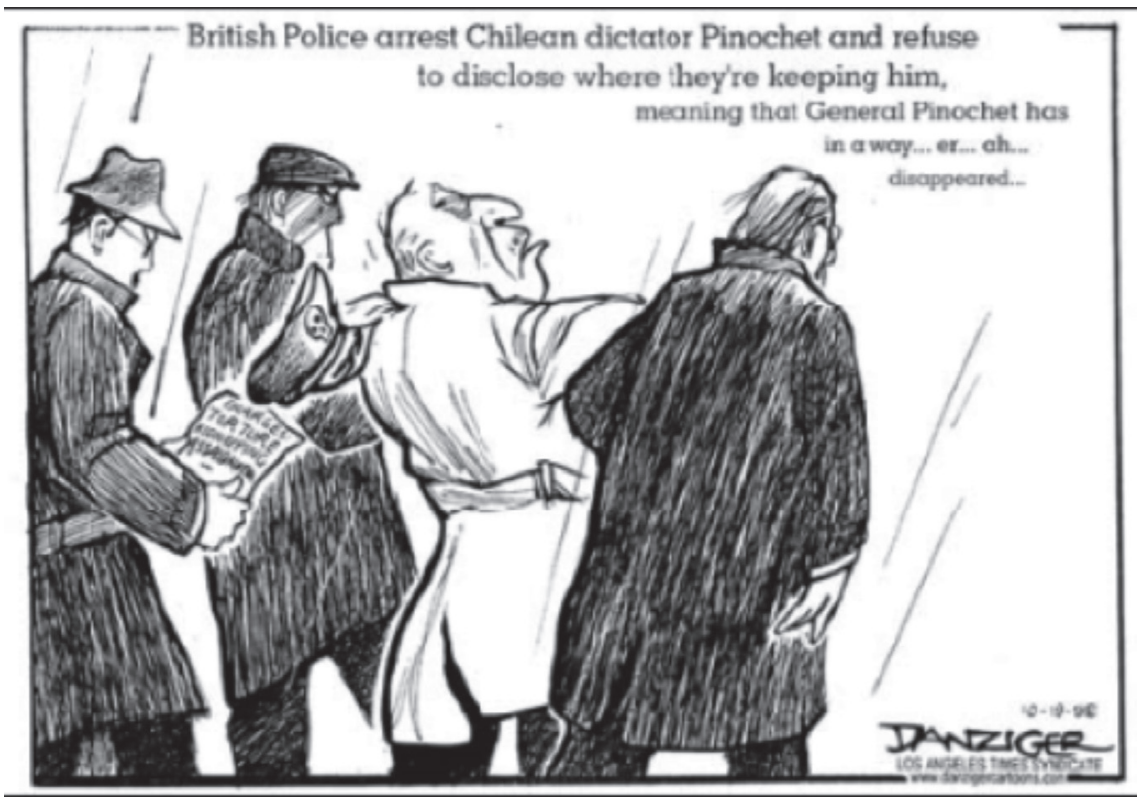

Figura 4. Jeff Danziger. Los Angeles Times, 26/11/1998.

El retorno de Pinochet al país, demandado por el gobierno de Chile aduciendo razones humanitarias y prometiendo juzgarlo bajo la legislación

\footnotetext{
${ }^{5}$ Prueba de esto último es la viñeta del dibujante Serguei publicada por el diario Le Monde pocos días después de la detención de Pinochet en Londres, donde se lo muestra como un horrible animal carnívoro expuesto en el Museo Británico.

${ }^{6}$ Conocido como "Informe Rettig", debido al nombre del abogado que la presidió, Raúl Rettig.
} 
chilena, no cerró el debate en torno a su persona y al legado de la dictadura $^{7}$. Por el contrario, fue en aumento hasta el año 2003, cuando se conmemoraron los 30 años del golpe de Estado, que además coincidió poco tiempo después con el escándalo de las cuentas bancarias del caso Riggs y la creación de la Comisión sobre Prisión Política y Tortura ${ }^{8}$, que publicó su informe final en 2005. Desde esta fecha hasta la muerte del general, en 2006, su imagen no hizo sino degradarse incluso entre sus partidarios, a lo que se sumaban las condenas judiciales de numerosos militares por casos de violaciones a los DD.HH. ocurridas antes de 1990.

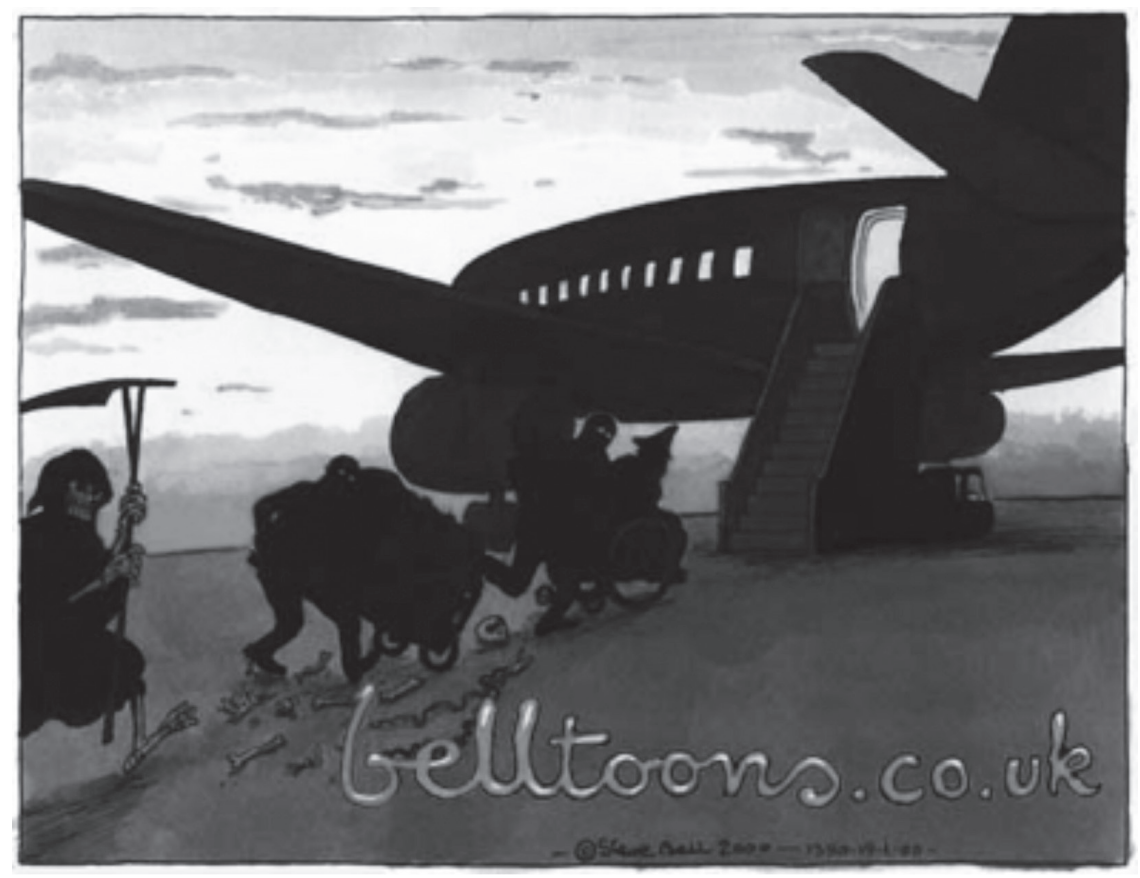

Figura 5. Steve Bell, The Guardian, 04/01/2000.

Los funerales de Pinochet dividieron al país nuevamente entre sus seguidores y sus detractores, pero lo que es evidente es que su imagen negativa se fue instalando en la gran mayoría de la población. Esto último

${ }^{7}$ La viñeta del dibujante Steve Bell del 04 de enero de 2000 (v. fig. 5), da cuenta del ambiente en el cual Pinochet dejaría Inglaterra: liberado por razones humanitarias y saliendo del país en la penumbra. Fue así como lo mostró el diario británico The Guardian.

${ }^{8}$ Conocida como "Comisión Valech", debido al nombre del sacerdote que la presidió, Sergio Valech. 
conlleva también un problema histórico similar al que generó el nazismo y la figura de Hitler para la historiografía alemana de posguerra, porque Pinochet finalmente ha concentrado en su persona todas las complejidades de un régimen donde participaron civiles y militares, y donde la mayoría de quienes se beneficiaron directa o indirectamente de él, no han asumido ninguna responsabilidad. Al personaje (Pinochet), una vez desaparecido, se le carga simbólicamente con todos los aspectos más negativos del periodo, liberando a quienes lo sobreviven y fueron parte activa y usufructuaron de la dictadura. Es por ello que su reivindicación solo puede venir de aquellos grupos más fieles a su legado, como ha sucedido en los últimos años?.

La conmemoración de los 40 años del golpe en septiembre de 2013 no hizo sino ahondar la crítica al régimen y a la figura de Augusto Pinochet en particular. A esto se sumaron las críticas del Presidente de la República de la época, Sebastián Piñera, al referirse a los "cómplices pasivos de la dictadura", en el mismo momento en que se suicidaba en prisión el general Odlanier Mena, quien había dirigido uno de los principales órganos represivo del régimen, la CNI, durante la década de 1980. Estos dos acontecimientos, aparentemente inconexos, dieron cuenta de una lectura cada vez más crítica sobre el periodo. A partir de aquel año, solo algunos dirigentes de la derecha política más liberal comenzaron a hablar del periodo como "la dictadura" y no como el "gobierno militar", cuestión inédita hasta el momento, pues también reconocieron la brutalidad de las violaciones a los DD.HH. y la responsabilidad política e incluso penal que le cupo a Pinochet en los hechos.

Dicho lo anterior, no es menos cierto que en Chile la disputa en torno a la imagen de Pinochet y del régimen que encabezó tiene muy poca relación con la representación que buena parte del mundo se hizo sobre el personaje. En nuestras investigaciones recientes sobre la caricatura política de prensa sobre Pinochet en Inglaterra, Francia y Estados Unidos durante el periodo 1973-2006, se puede constatar, sin mayor dificultad, que el juicio negativo respecto de su papel durante la dictadura es absolutamente mayoritario, y es un consenso prácticamente indiscutido en los medios académicos y en los distintos sectores políticos. Augusto Pinochet aparece como una figura vinculada a la traición, la cobardía y la violencia represiva, especialmente producto de la cobertura global de prensa que recibió durante su detención en Londres.

\footnotetext{
${ }^{9}$ Ver la encuesta MORI-CERC del año 2015 sobre la imagen que tienen los chilenos de la figura de Augusto Pinochet.
} 
Solo en Chile persiste esta disputa en torno a la figura de Pinochet, quien poseería una suerte de apoyo popular no confesado, y que alguna vez se evidenció en el $44 \%$ de los votos obtenidos por la opción Sí en el plebiscito de 1998, o en el masivo adiós que se le dio en la Escuela Militar durante su velorio en diciembre de 2006. Y es justamente aquí donde el estudio del pasado nos permite comprender el porqué de la polémica en torno a la imagen de Pinochet incluida en una exposición del Museo Histórico Nacional del año 2018, originalmente dedicada al desarrollo de la idea de la libertad durante los 200 años de vida independiente de Chile.

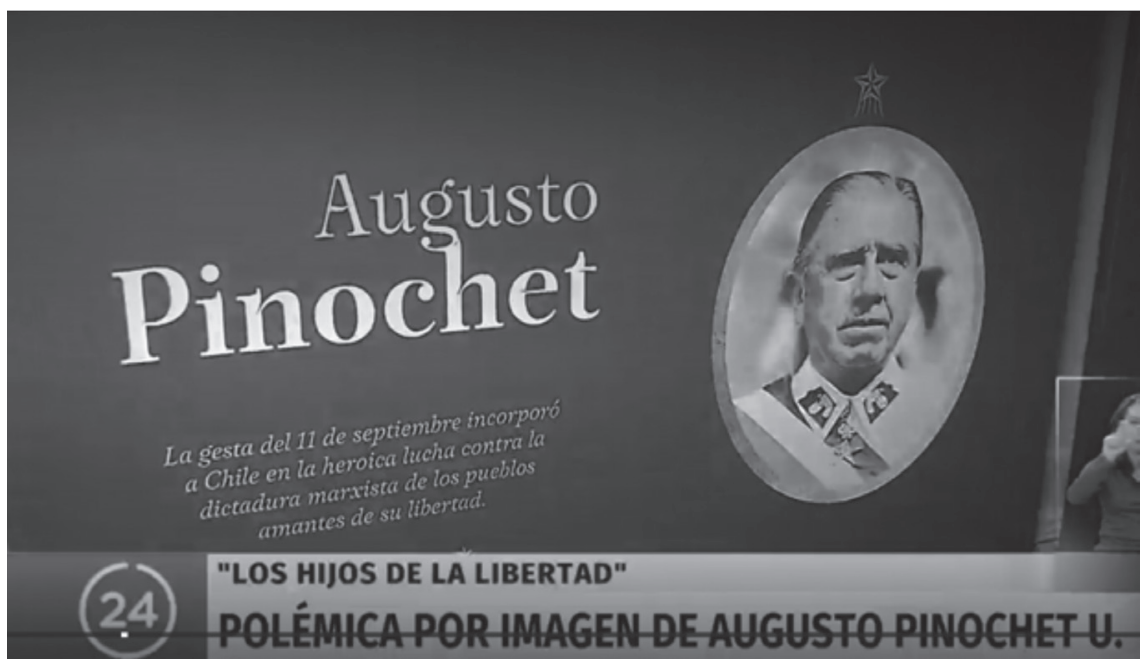

Figura 6. Cita de Pinochet incorporada en la exposición "Hijos de la Libertad" del MHN (2018). Nota de TVN. 24 hrs. (08-05-2018). Disponible en: https://www.24horas. $\mathrm{cl} /$ nacional/polemica-por-figuracion-de-augusto-pinochet-en-exposicion-del-museohistorico-nacional-2707158

El problema no estuvo solo en que Pinochet fuera incluido junto a otros próceres de la historia nacional que lucharon por la libertad, la democracia y los derechos sociales, sino en que su simple mención en un panel al final de la muestra pudo arruinar toda la curatoría de una exposición planeada durante meses. Es a eso a lo que llamamos el "efecto Pinochet"10, pues desborda todo análisis histórico para entrar en el campo de las emociones y

\footnotetext{
${ }^{10}$ Este concepto ya había sido utilizado el 18 de septiembre de 1999 en una editorial del periódico español El País, donde se hacía alusión a cómo el personaje y su detención en Londres habían "envenenado" las relaciones diplomáticas entre España y Chile (ver Anónimo, 1999).
} 
las sensibilidades. Si a eso se suma el conocimiento que los chilenos hemos tenido de la imagen del dictador fuera del país, sobre todo a partir de la masificación de Internet, no es difícil de imaginar el revuelo que causó su inclusión en un museo de historia donde se quiso aludir al concepto de libertad. La contradicción surgió justamente porque a Pinochet se le asocia, tanto en Chile como en el extranjero, con un régimen liberticida, y, por lo tanto, su asociación con la idea de la libertad solo podía funcionar en tanto provocación. Si esto además ocurría en un museo visitado principalmente por escolares, turistas y público no académico, se daban todos los ingredientes para una polémica, como efectivamente sucedió en mayo de 2018. Lo paradójico del asunto es que la exposición estuvo abierta durante varias semanas sin el menor incidente, y solo cuando un joven parlamentario del Frente Amplio (Giorgio Jackson) posteó en sus redes sociales la imagen de Pinochet asociada a una frase suya sobre la libertad y la derrota del marxismo, fue que se desató el conflicto.

Evidentemente Augusto Pinochet y su legado pueden y deben ser estudiados y expuestos a la luz en el espacio público, pues la imagen de la monstruosidad no puede inhibirnos a comprender nuestro pasado reciente y el peso de su figura en el presente. Sin embargo, la cuestión debe tratarse teniendo en cuenta los antecedentes expuestos anteriormente, la representación que se ha hecho Chile y el mundo del personaje, pero sobre todo el cuidado y la responsabilidad que deben tener las instituciones culturales como el MHN para no confundir ni menos considerar a un museo histórico como un espacio para la provocación, pues aquí no se trata ni de arte contemporáneo ni de vanguardias estéticas, sino de trabajar un periodo que aún nos marca con sus huellas de horror y sufrimiento.

La exposición del Museo Histórico Nacional titulada "Hijos de la Libertad. 200 años de Independencia”, abierta al público en abril de 2018, contó con el apoyo de diversos y reconocidos profesionales, entre los cuales había historiadores del arte y de la política ${ }^{11}$. Esto puede advertirse en el cuidado puesto en el guión que acompañó la muestra. En estos documentos puede advertirse una mirada genealógica en torno a la idea de libertad y las tensiones globales que esta generó tras la Revolución Francesa. La museografía

\footnotetext{
${ }^{11}$ El guion original de la exposición puede ser descargado directamente desde el sitio web del MHN. Documento disponible en: https://www.mhn.gob.cl/618/articles-85161_archivo_01.pdf. Entre los profesionales que participaron en la elaboración del guion estuvieron: los historiadores Patricio Arriagada y Bárbara Silva; los historiadores del arte Juan Manuel Martínez y Marcela Covarrubias; el Doctor en Estudios Latinoamericanos Luis Alegría, y el antropólogo y ex director del MHN Pablo Andrade.
} 
contaba con alrededor de 600 objetos e imágenes que daban cuenta de la evolución de la idea de libertad en Chile durante los últimos 200 años, y una serie de textos explicativos sobre figuras públicas que utilizaron el concepto y objetos e imágenes que lo representaron.

La dictadura militar de 1973-1990 formaba parte del último capítulo de la muestra, pero sin una dedicación particular, pues no era el objetivo de la exposición. La polémica se desató a partir del último panel de la muestra donde aparecían diferentes figuras de la historia nacional citadas por el uso que hicieron de la palabra "libertad". Y es en esta cuestión propia de la museografía, en el último instante de una muestra en general bien curatoriada, donde se produce el conflicto memorial: en dicho panel aparecía una fotografía de Pinochet, muy cerca de una imagen de Salvador Allende, junto a la siguiente frase: "La gesta del 11 de septiembre incorporó a Chile en la heroica lucha contra la dictadura marxista de los pueblos amantes de su libertad ". Fue esta frase y la ubicación de Pinochet entre otras figuras democráticas, intelectuales y artísticas de la historia chilena, lo que desató la crisis. Esto no podría haber ocurrido sin esta tensión nunca totalmente resuelta entre la imagen nacional e internacional del ex-dictador y los conflictos memoriales que su figura aún genera.

En definitiva, podemos concluir que la imagen internacional de Pinochet construida a lo largo de más de cuarenta y cinco años recién comenzó a ser realmente percibida en Chile a partir de su detención en Londres en 1998, y que posteriormente no ha hecho más que deteriorarse. Ambas percepciones comienzan a coincidir en sus aspectos más negativos, y aquello pudo ser percibido claramente en la polémica del MHN y el contexto en el que se incluyó al personaje al final de la exposición. A medida que pasa el tiempo y se conoce más sobre el periodo de la dictadura y la transición, la imagen de Pinochet construida en el extranjero coincide más con aquella que tiene actualmente la mayoría de los chilenos.

Es bastante claro que la figura de Pinochet divide a nuestra sociedad, pero además está asociada a un sinnúmero de aspectos negativos que hacen muy difícil su reivindicación histórica futura (aunque no imposible) y más aún su asociación con el concepto de libertad, salvo que esta última se la restrinja solo al aspecto económico. Lo que resulta evidente es que esta no será ni la primera ni la última polémica en torno a su representación y significado en el espacio público. 


\section{REFERENCIAS}

Amaral de Aguiar, C. (2015). Noticias del "fin del mundo": el Chile de la Unidad Popular y el golpe de Estado en la TV francesa. Nuevo Mundo Mundos Nuevos, 15 [En ligne]. http://journals.openedition.org/nuevomundo/67986; DOI : $10.4000 /$ nuevomundo.67986.

Angell, A. (2003). The Chilean Coup of 1973: a perspective thirty years later. Oxford: St Antony's College.

Angell, A. (2013). Las dimensiones internacionales del golpe de Estado chileno. Revista de Ciencia Política, 2, 57-78.

Anónimo (1999). Editorial “El efecto Pinochet”. Diario El País. 17-09-1999. Disponible en: https:/elpais.com/diario/1999/09/18/opinion/937605601_ 850215.html.

Araya, F. (2007). Historia de la revista APSI: el que se ríe se va al cuartel (pico para Pinochet). Santiago. Lom.

Ayala, M. y Rojas, C. (2017). La recepción de los golpes de Estado de Chile y Argentina en Venezuela: prensa, actores políticos y gobiernos (1973/1976). Izquierdas 33, 1-20. https://dx.doi.org/10.4067/S0718-50492017000200001.

Baridon, L. \& Guédron, M. (2006). L'Art et l'histoire de la caricature. Des origines à nos jours. Paris: Citadelles \& Mazenod.

Bell, S. (2000, 4 january). Caricatura. The Guardian, 3.

Birns, L. (1973, 1 november). The Death of Chile. The New York Review of Books, 6. Disponible en: https://www.nybooks.com/articles/1973/11/01/ the-death-of-chile/

Danziger, J. (1998, 26 november). Caricatura. Los Angeles Times, 1.

Delporte, C., Mollier, J. \& Sirinelli, J. (2010). Dictionnaire d'histoire culturelle de la France contemporaine. Paris: PUF.

Dobritz, J. (1983, 18 mai). Caricatura de Pinochet, La Croix.

Gárate, M. (2015). El nacimiento de un monstruo. Caravelle, 104, 87-114. DOI: $10.4000 /$ caravelle.1588.

Gombrich, E. H. (1984). The Experiment of Caricature, chapitre X. Art and illusion, A study in the Psychology of Pictorial Representation (pp. 265-288). Princeton: Princeton University Press.

Gombrich, E. H. (2007). The Cartoonist's Armoury. Meditations on a Hobby Horse and other essays on the theory of art (4a ed., 3a reimpr., pp. 127-142). New York: Phaidon.

Gutiérrez, M. (2013, 2 de septiembre). Chas Gerretsen, el fotógrafo tras la imagen más terrorífica de Pinochet: Él era un monstruo. The Clinic [en línea]. Disponible en: https://www.theclinic.cl/2013/09/02/chas-gerretsen-el-fotografo-tras-la-imagen-mas-terrorifica-de-pinochet-el-era-un-monstruo/.

Joignant, A. (2007). Un día distinto. Memorias festivas y batallas conmemorativas en torno al 11 de septiembre en Chile 1974-2006. Santiago: Editorial Universitaria. 
Karmy, R. (2007). ¿Qué es "Pinochet"? (Violencia, derecho y vida). Nuevo Mundo Mundos Nuevos, 7 [en línea]. Disponible en: http://nuevomundo. revues.org/3822.

Monsteroftheid (2018). Ilustración artística de Pinochet derivada de la foto original de Chas Gerretsen. Recuperada de Devian Art. Disponible en: https://www.deviantart.com/monsteroftheid/art/Pinochet-123194320 Visitado el 20-05-2019.

Montealegre, J. (2008). Historia del humor gráfico en Chile. Santiago: Milenio.

MORI, CERC (julio, 2015). La imagen de Pinochet y la Dictadura, Barómetro de la Politica. Disponible en: http://morichile.cl/imagen-del-pinochetismobarometro-de-la-politica-cerc-mori-2015/.

Nota de TVN. 24 hrs. (2018, 8 de mayo). Disponible en: https://www. 24horas. $\mathrm{cl} /$ nacional/polemica-por-figuracion-de-augusto-pinochet-en-exposiciondel-museo-historico-nacional-2707158.

Plantu (Jean Plantureaux). (1973, 13 nov.). Le Monde, 1.

Riss (Laurent Sourisseau) (1999, 2 de junio). Caricatura de Pinochet. Charlie Hebdo.

Van Ypersele, L. (1993). La caricature et l'historien. En L. Courtois et J. Pirotte (dir.). Images de la Wallonie dans le dessin de presse (1910-1961). Une enquête dans la presse daction wallonne (pp. 113-117). Louvain-la-Neuve: Fondation wallonne Pierre-Marie et Jean-François Humblet.

Vayssière, P. (2005). Le Chili d'Allende et de Pinochet dans la presse française. Passions politiques, information et désinformation. Paris: L'Harmattan. 